\title{
Absolute requirement for STAT3 function in small-intestine crypt stem cell survival
}

\author{
JR Matthews ${ }^{1}$, OJ Sansom ${ }^{2}$ and AR Clarke ${ }^{\star, 1}$
}

\begin{abstract}
The transcription factor signal transducer and activator of transcription 3 (STAT3) is frequently activated in human cancers. Interestingly, STAT3 also maintains the pluripotency and self-renewal of murine embryonic stem cells, and several tissue stem cell types. To investigate whether STAT3 also maintains the small-intestine crypt stem cell, we conditionally inactivated a Floxed Stat3 allele $\left(\right.$ Stat $\left.^{t}\right)$ in murine small-intestine crypt stem cells. Following Cre recombinase expression, apoptosis increased in Stat $3^{f / /}$ experimental crypts relative to Stat $3^{\text {wt/- }}$ controls before declining. Control Stat3 ${ }^{\text {wt/- }}$ mice carrying a Flox-STOP LacZ reporter transgene stably expressed LacZ after Cre induction. In contrast, Stat $3^{f / /-}$ intestine LacZ expression initially increased modestly, before declining to background levels. Quantitative PCRs revealed a similar transient in recombined Stat $3^{f l}$ allele levels. Long-term bromodeoxyuridine labelling directly demonstrated that functional STAT3 is required for +4 to +6 region label-retaining small-intestine stem cell survival. Rapid clearance of recombined Stat3 ${ }^{f / \nu}$ cells involves apoptosis potentially induced by elevated c-Myc in non-recombined cells and involves elevated p53 expression and caspase 3 activation. Intriguingly, Stat $3^{f / /}$ intestine recombination triggered dramatically upregulated polycomb transcriptional repressor Bmi 1 - potentially accelerating recombined crypt repopulation. In summary, STAT3 activity is absolutely required for small-intestine crypt stem cell survival at both the +4 to +6 label-retaining and crypt base columnar cell locations.
\end{abstract}

Cell Death and Differentiation (2011) 18, 1934-1943; doi:10.1038/cdd.2011.77; published online 3 June 2011

The signal transducer and activator of transcription (STAT) family of transcription factors are activated in response to extracellular cytokine and growth factor ligands. Classically, following phosphorylation at a single-tyrosine residue by JAK family tyrosine kinases, STAT monomers dimerise via reciprocal phosphotyrosine-Src homology 2 (SH2) domain interactions, acquiring nuclear localisation activity and highaffinity DNA-binding activity to activate gene expression. ${ }^{1,2}$ Inappropriate activation of STAT family members, especially STAT3, occurs in numerous human cancers and cancer cell lines. $^{3,4}$ STAT3 activation is also critical for maintaining pluripotency and preventing differentiation of murine embryonic stem (mES) cells. Thus, inducible expression of a dominant negative interfering STAT3F mutant in mES cells abolished their self-renewal and promoted differentiation. ${ }^{5}$ STAT3 function is also important in several tissue stem cell types - for example, porcine skin stem cells express STAT3 at high levels. ${ }^{6}$ Similarly, transduction of murine haematopoietic stem cells with a dominant negative STAT3-expressing retrovirus caused a large and permanent reduction in their in vivo lympho-myeloid reconstituting ability. ${ }^{7}$

Here, we examine the requirement of murine small-intestine crypt stem cells for functional STAT3. The small-intestine epithelium undergoes constant renewal - a process dependent upon stem cells located near the crypt base. ${ }^{8}$ The crypt stem cells generate a population of rapidly proliferating cells the transit-amplifying cells - which undergo a limited number of divisions while migrating up the crypt. On reaching the crypt-villus junction, these transit-amplifying cells exit the cell cycle and terminally differentiate, yielding mature enterocytes, goblet cells and enteroendocrine cells, which migrate towards and eventually shed from, the villus tip. The crypt base, in contrast, comprises two other cell types - Paneth cells and slowly proliferating crypt base columnar (CBC) cells. The precise identity of the small-intestine crypt stem cell has been controversial for many years, with one long-accepted candidate being the radiation-hypersensitive, long-term labelretaining cell located at the +4 to +6 positions from the crypt base. ${ }^{9}$ Another long-time crypt stem cell candidate, the $\mathrm{CBC}$ cell interleaved between crypt base Paneth cells ${ }^{10}$ has attracted renewed interest following studies demonstrating that Lgr5-expressing $\mathrm{CBC}$ cells can regenerate all the cell types in the small-intestine crypt-villus unit, ${ }^{11}$ and indeed, can generate crypt-like structures in vitro with self-renewal activity. ${ }^{12}$

Given the importance of aberrantly activated STAT3 in many cancers, the resurgent interest in the cancer stem cell concept as a therapeutic target, and the importance of STAT3 function in mES and several tissue stem cell types, we investigated STAT3's role in the murine small-intestine crypt.

\footnotetext{
${ }^{1}$ Division of Pathophysiology and Repair, School of Biosciences, Cardiff University, Cardiff, UK and ${ }^{2}$ CRUK Beatson Institute for Cancer Research, Bearsden, Glasgow, UK ${ }^{*}$ Corresponding author: AR Clarke, Division of Pathophysiology and Repair, School of Biosciences, Cardiff University, Museum Avenue, Cardiff CF10 3AX, UK. Tel: + 442920 874609; Fax: + 442920 876328; E-mail: ClarkeAR@cf.ac.uk Keywords: adult stem cells; conditional knockout; Cre-lox P system; long-term repopulation; STAT; self-renewal Abbreviations: AH-Cre, Cyp1A1 promoter-Cre recombinase; BrdU, bromodeoxyuridine; CBC, crypt base columnar cell; Ct, threshold cycle; DAPI, 4',6-diamidino-2phenylindole; $\mathrm{Fl}$, floxed; $\mathrm{H}+\mathrm{E}$, haematoxylin plus eosin; HRP, horseradish peroxidase; mES, murine embryonic stem cell; NGS, normal goat serum; PcG, polycomb group; Q-PCR, quantitative polymerase chain reaction; SH2, src homology 2; STAT, signal transducer and activator of transcription; TBS, Tris-buffered saline; WT, wild type; -, null

Received 26.10.10; revised 12.4.11; accepted 27.4.11; Edited by G Melino; published online 03.6.11
} 
We used an inducible cytochrome P450 Cyp1A1 promoterCre recombinase $(A H-C r e)$ transgene $^{13}$ and a Stat3 allele carrying LoxP sites flanking the exon encoding STAT3's tyrosine 705 residue $\left(\text { Stat } 3^{\text {th }}\right)^{14}$ to conditionally inactivate STAT3 in murine small-intestine crypts in response to treatment with the xenobiotic $\beta$-naphthoflavone. The inducible $A H$-Cre transgene allows Cre expression in both the CBC crypt stem cells and in the +4 to +6 position long-term labelretaining crypt stem cells. ${ }^{15}$ The second Stat 3 allele in both control and experimental mice was a Null(-) allele whose exons encoding the $\mathrm{SH} 2$ domain and the tyrosine 705 residue have been removed - yielding a STAT3 protein which cannot undergo dimerisation. ${ }^{16}$

In this study, we provide evidence that STAT3 function is necessary for the survival of both the murine small-intestine crypt +4 to +6 position long-term label-retaining stem cell and the slowly proliferating CBC stem cell.

\section{Results}

Use of a Flox-STOP LacZtransgene reveals the transient appearance and subsequent loss of STAT3-null crypts. The Flox-STOP LacZ reporter transgene was used as a surrogate marker of recombined small-intestine crypts. By 1 day after the induction of Cre expression, the control Stat $^{\text {wt/- }}$ small intestine expressed LacZ activity at medium level, whereas the experimental Stat $3^{f / /}$ intestine expressed low levels of LacZ activity. By 2 days post induction, the control Stat ${ }^{w t /-}$ intestine showed homogeneous high-level LacZ activity, whereas the experimental Stat ${ }^{f l /}$ - intestine showed only a modest rise in LacZ activity. By 3 days post induction, the control intestine retained high-level LacZ expression as expected. In contrast, the Stat3 ${ }^{f / /}$ - intestine showed essentially no macroscopically observable LacZ activity (Figure 1a). Cross-sections of day 3 experimental and control small intestines demonstrated LacZ staining consistent with Cre-recombined Flox-STOP LacZ cells migrating out of the crypt (Figure 1b). Stripping away the smooth muscle layer allowed direct examination of the smallintestine crypt bases. By 3 days post induction, virtually $100 \%$ of Stat $3^{\text {wt }}$ - crypt bases had strong LacZ staining, reflecting the continued viability of the Stat ${ }^{w t /}$ crypt stem cell(s). In contrast, in the Stat ${ }^{f l /-}$ experimental intestine, virtually none of the crypt bases retained any LacZ staining activity (Figure 1c).

To confirm that the Stat ${ }^{f / /}$ small intestine was functionally STAT3 null following Cre induction, anti-STAT3 immunohistochemistry was performed using the New England Biolabs/ Cell Signaling Technology \#9132 (NEB/CST\#9132; NEB/ CST, Ipswich, MA, USA) antibody (recognising an epitope around the STAT3 tyrosine 705 residue) - this revealed a loss of STAT3 immunoreactivity from the Stat3 ${ }^{f /-}$ small-intestine crypts by 1.7 days post induction relative to the Stat3 ${ }^{w t /}$ control (Figure 1d). To confirm that STAT3 is constitutively activated in the crypt epithelium, immunohistochemistry was performed using the NEB/CST \#9131 antibody, which recognises tyrosine 705 phosphorylated STAT3. This revealed frequent, strong, nuclear phosphotyrosine 705 immunoreactivity in un-induced Stat $3^{\text {wt }-}$ control crypt epithelial

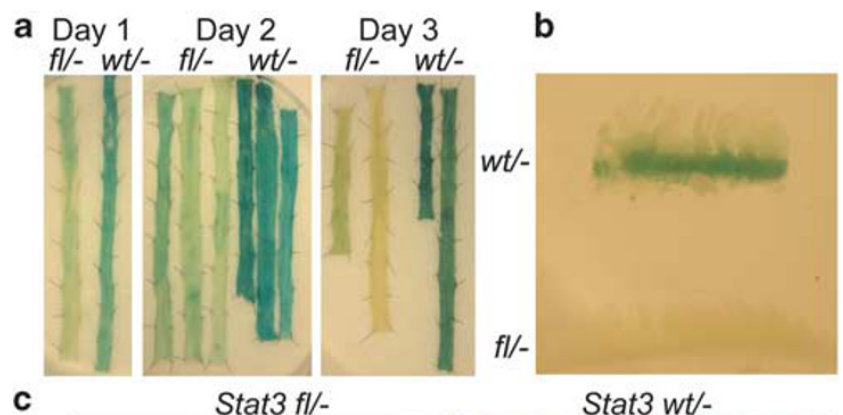

C
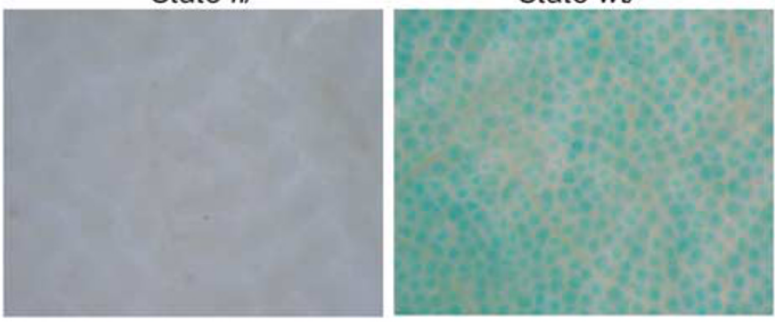

d
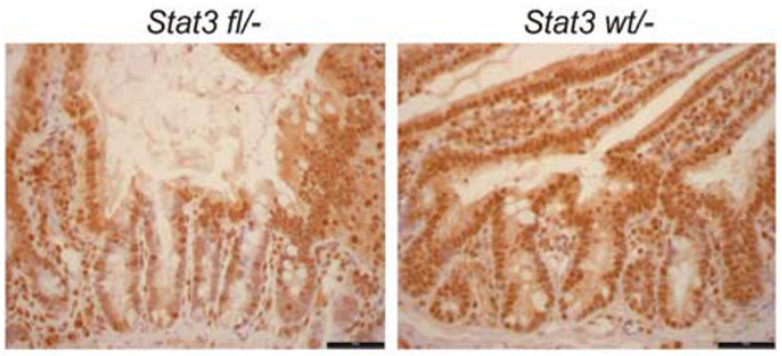

e
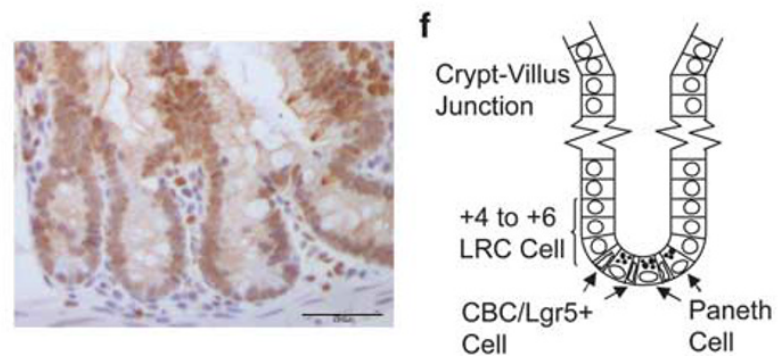

Figure 1 Use of a Flox-STOP LacZ transgene as a surrogate marker of Stat3 ${ }^{t}$ recombination to visualise the transient appearance and disappearance of STAT3null crypts. (a) LacZ enzyme activity in Stat3 ${ }^{f /-}$ and Stat3 ${ }^{\text {wt }-}$ small intestine at 1, 2 and 3 days after $\beta$-naphthoflavone injection/induction of Cre expression. (b) Crosssection of small intestine showing LacZ enzyme activity in Stat $3^{\text {fl/ }}$ and Stat $3^{\text {wt- }}$ mice at 3 days after $\beta$-naphthoflavone injection/induction of Cre expression. (c) Crypt bases in Stat ${ }^{\text {fl/-}}$ and Stat ${ }^{\text {wt }-}$ small intestine at 3 days following $\beta$-naphthoflavone injection/induction of Cre expression viewed at high power $(\times 90$ magnification) after removal of the smooth muscle layer. LacZ enzyme activity panels are representative of three Stat $3^{\text {t// }}$ versus three Stat $3^{\mathrm{wt} /}$ - mice per time point. (d) Anti-STAT3 immunoreactivity (with the NEB/CST \#9132 primary antibody recognising an epitope close to the STAT3 tyrosine 705 residue) in Stat ${ }^{\text {fl }}-$ versus Stat3 $^{\text {wt/ }}$ - small intestine at 1.7 days after induction of Cre expression. Immunohistochemistry panels are representative of three Stat3 $3^{\text {t/ } /}$ versus three Stat $3^{\text {wt }-}$ mice, the black bars represent $50 \mu \mathrm{m}$. (e) Anti-STAT3 phosphotyrosine 705 immunoreactivity (using the NEB/CST \#9131 primary antibody) in un-induced Stat ${ }^{\text {wt/ }}$ control small intestine. The panel is representative of three Stat $3^{\text {wt }-}$ mice, the black bar represents $50 \mu \mathrm{m}$. (f) Schematic of the small-intestine crypt base showing the thin $\mathrm{CBC} / \mathrm{Lgr5}{ }^{+}$slowly proliferating stem cells interleaved by Paneth cells with the over-lying +4 to +6 region containing long-term, label-retaining, quiescent stem cells 
cells (Figure 1e). The small-intestine crypt $\mathrm{CBC}$ and +4 to +6 position stem cell locations where $\mathrm{AH}$-Cre transgene expression is induced following $\beta$-naphthoflavone treatment are illustrated (Figure 1f).

Individual crypt cell position immunohistochemical analysis of Stat $^{f / /}$ versus Stat $3^{\text {wt/- }}$ small-intestine epithelium reveals a wave of functionally STAT3-null cells moving up the crypt. Immunohistochemistry using the NEB/CST \#9132 antibody (recognising an epitope around the STAT3 tyrosine 705 residue) was performed on Stat $^{f l /-}$ and Stat ${ }^{\text {wt/- }}$ small intestine from $1.7,2$ and 3 days after Cre induction. Individual crypt cell positions were assessed for STAT3 staining intensity in 56 half-crypts. To avoid cells with a low level of expression of intact STAT3 confounding the signal from cells which no longer possessed a functional Stat $3^{f l}$ allele, only crypt cells showing absolutely no traces of anti-STAT3 \#9132 immunoreactivity (nuclear or cytoplasmic) were counted as negative. By 1.7 days after Cre induction, there was a clearly elevated frequency of STAT3negative cells in the bottom quarter of the Stat $3^{f / /}$ crypts relative to the Stat $3^{w t /-}$ crypts (Figure 2a). By 2 days, the elevated STAT3-negative cell frequency was apparent over most of the length of the Stat $3^{f /-}$ crypts relative to the Stat ${ }^{w t /-}$ crypts (Figure $2 b$ ), while by 3 days, the elevated STAT3-negative cell distribution was confined to the upper half of the Stat $3^{f / /}$ crypts relative to the Stat ${ }^{\text {wt }}$ - crypts (Figure 2c) - consistent with a wave of functionally STAT3null cells migrating upwards from the base of the Crerecombined Stat3 ${ }^{f / l-}$ crypts.

A surge in apoptotic index in Stat $^{f I /-}$ small-intestine crypt epithelium at 2 days post induction of Cre recombinase expression. Following Cre induction, mice were harvested at various time points and apoptotic and mitotic indices counted from 56 half-crypts in the first $8 \mathrm{~cm}$ of (methacarn-fixed, Mayer's haematoxylin and eosin $(\mathrm{H}+\mathrm{E})$ stained) small intestine. The apoptotic indices in both Stat ${ }^{f /-}$ and Stat $^{\text {wt/- }}$ small-intestine crypts increased modestly by 1.7 days after Cre induction. By 2 days after Cre induction, the Stat3 ${ }^{w t /}$ control crypt average apoptotic index had essentially returned to baseline values $(1.443 \%)$, whereas the Stat $3^{f / /}$ crypt average apoptotic index had increased dramatically $(3.803 \%)$ and statistically significantly $\left(P=0.0404, N=3\right.$ Stat $^{f / /}{ }^{-}$versus 3 Stat $\left.^{\text {wt } /-}\right)$ versus the control (Figure 3a). A statistically significant increase in apoptotic index in Stat3 ${ }^{f /-}$ crypts versus Stat3 ${ }^{w t /}$ controls was also observed at 3 days (2.43 versus $1.513 \%$, $P=0.0404, N=3$ Stat $^{f l /-}$ versus 3 Stat $^{w t /-}$ ), while by 4 days after induction, the $S t a t 3^{f / /}$ apoptotic index had returned to the baseline values of the Stat ${ }^{\text {wt/- }}$ control crypts.

However, examination of the Stat $3^{f / /}$ small-intestine crypt mitotic indices and average crypt cell number showed no statistically significant differences compared with Stat3 ${ }^{w t /}$ control crypts (Figures $3 b$ and $c$ ). Similarly, there were no obvious changes in crypt-villus phenotype in Stat3 ${ }^{f /-}$ versus Stat ${ }^{w t /-}$ small intestine following two cycles of Cre induction (at 4 and 8 weeks after birth), followed by aging mice for 1-2 years (see Supplementary Figure S1).
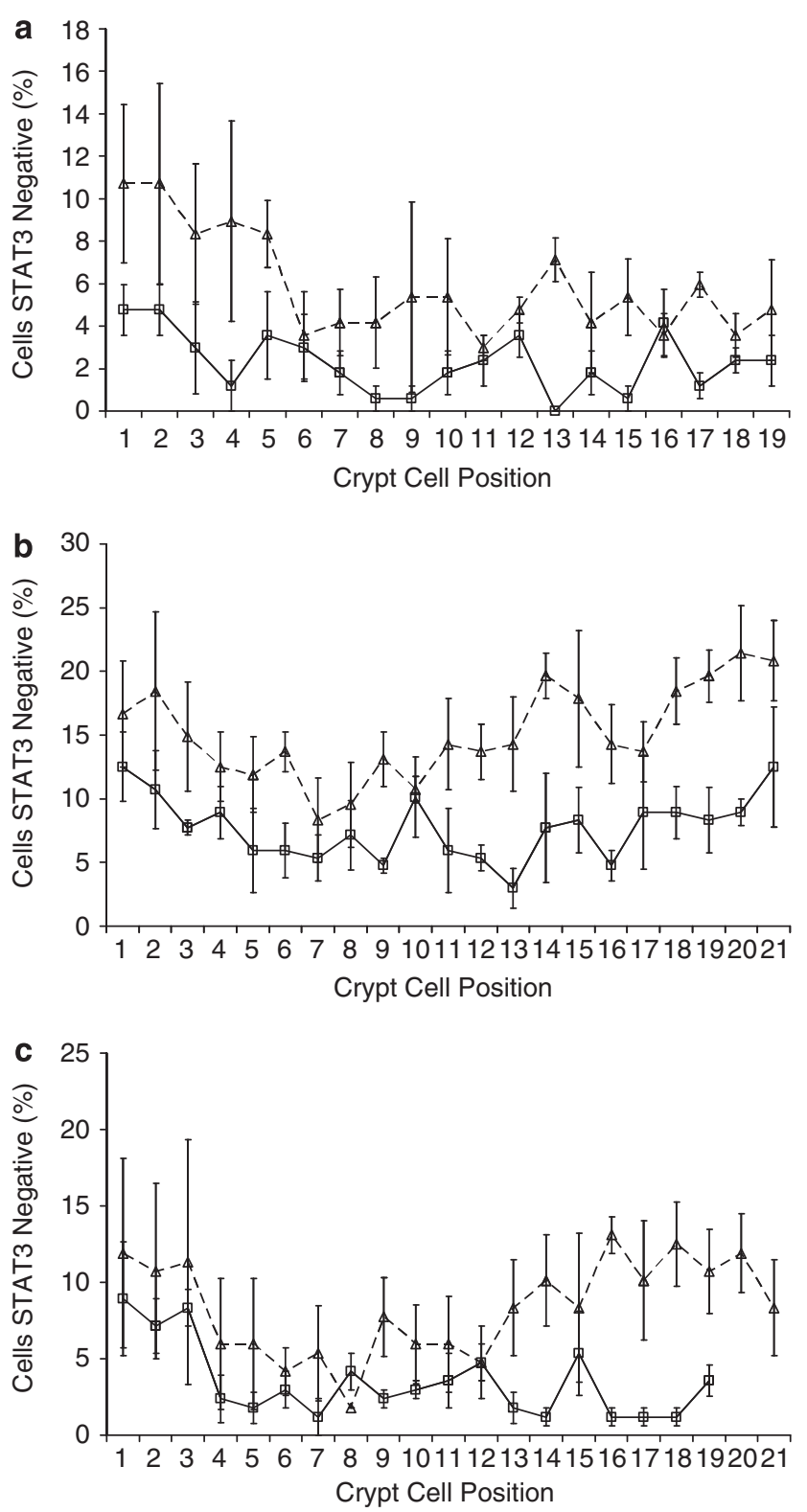

Figure 2 Use of anti-STAT3 immunohistochemistry to trace migration of functionally STAT3-null small-intestine crypt epithelial cells after induction of Cre expression. (a) Average frequency of cells lacking any anti-STAT3 immunoreactivity for Stat $^{f / /}-$ (dashed line/triangles) and Stat3 ${ }^{\text {wt/- }}$ (solid line/squares) crypts at individual crypt cell positions at 1.7 days after $\beta$-naphthoflavone injection/induction of Cre recombinase expression. (b) Average frequency of cells lacking any antiSTAT3 immunoreactivity for Stat $3^{\text {t//- }}$ (dashed line/triangles) and Stat ${ }^{\text {wt } /-}$ (solid line/squares) crypts at individual crypt cell positions at 2 days after $\beta$-naphthoflavone injection/induction of Cre recombinase expression. (c) Average frequency of cells lacking any anti-STAT3 immunoreactivity for Stat $3^{\text {th/- }}$ (dashed

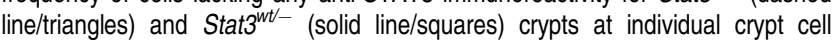
positions at 3 days after $\beta$-naphthoflavone injection/induction of Cre recombinase expression. The error bars indicate the values of the standard error of the mean (S.E.M.), $N=3$ Stat $^{\text {tl/ }}$ versus 3 Stat $^{\text {wt/ }}$ mice per time point

When the overall apoptotic indices were broken down into apoptotic frequencies at individual crypt cell positions, the apoptotic frequency had clearly increased at positions +5 and +6 up from the crypt base in Stat $3^{f / /}$ versus Stat ${ }^{\text {wt/- }}$ control crypts by 1.7 days post induction (Figure $4 a$ ). 

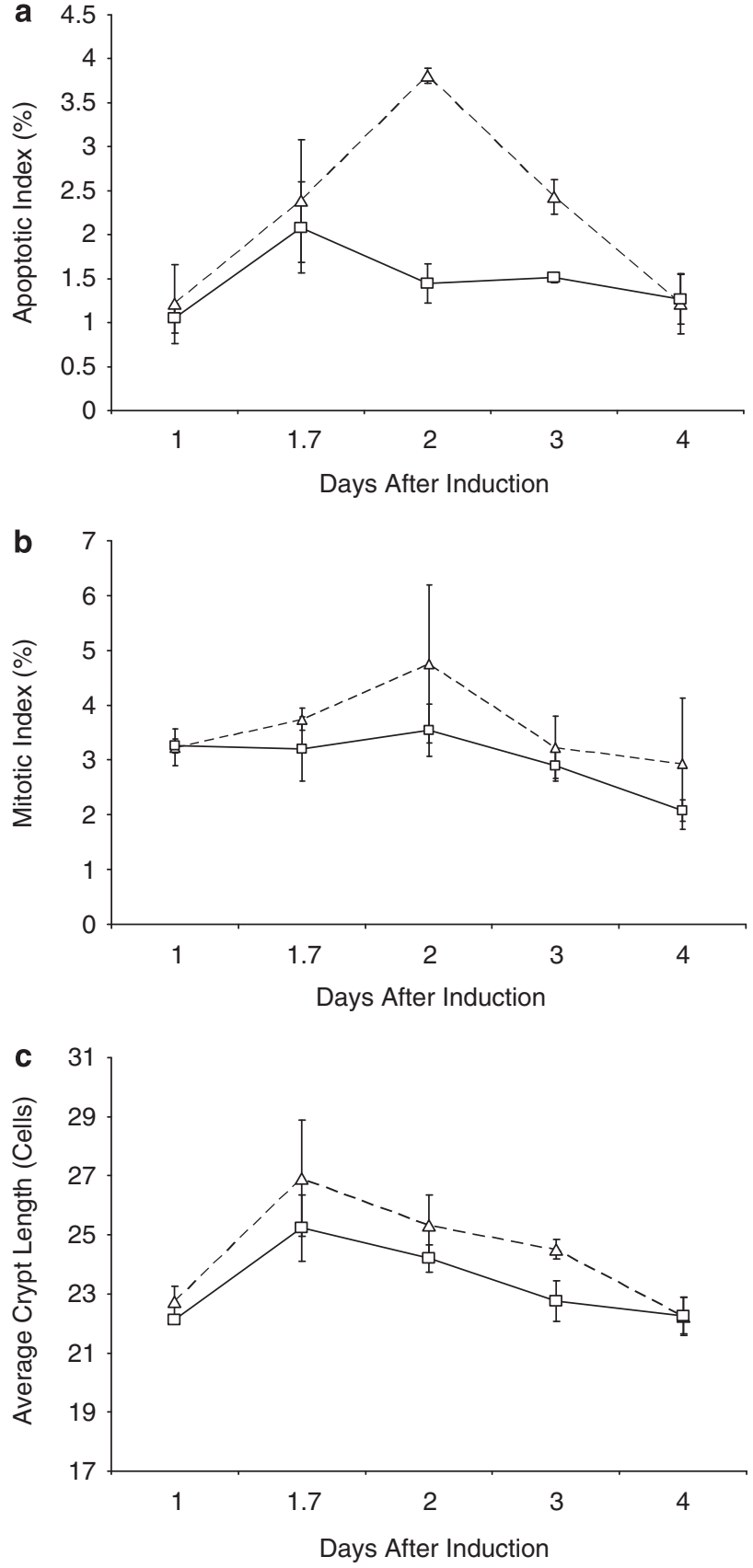

Figure 3 Changes in an average apoptotic and mitotic indices and average crypt length in Stat $3^{f l /-}$ and ${ }^{w t /-}$ small-intestine crypts in response to induction of Cre recombinase expression. (a) Apoptotic indices (average percentage of crypt cells undergoing apoptosis) in Stat ${ }^{f /-}$ (dashed line/triangles) and Stat ${ }^{\text {Wt }}$ - (solid $^{\text {(d) }}$ line/squares) crypts between 1 and 4 days following $\beta$-naphthoflavone-driven induction of Cre recombinase expression. (b) Mitotic indices (average percentage of crypt cells undergoing mitosis) in Stat $3^{f / /}$ (dashed line/triangles) and Stat3 ${ }^{\text {wt }}$ (solid line/squares) crypts between 1 and 4 days following induction of Cre expression. (c) Average length of small-intestine crypts in Stat ${ }^{f / /}-$ (dashed line/ triangles) and $S$ tat $3^{\text {wt }}$ - (solid line/squares) mice between 1 and 4 days following induction of Cre expression. The error bars indicate S.E.M. values, $N=3$ Stat $^{f / /-}$ versus 3 Stat $^{\text {wt }}$ - mice per time point

By 2 days post induction, there was a general increase in apoptotic frequency throughout the lower half of the Stat $3^{f /-}$

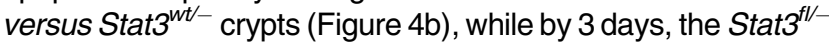
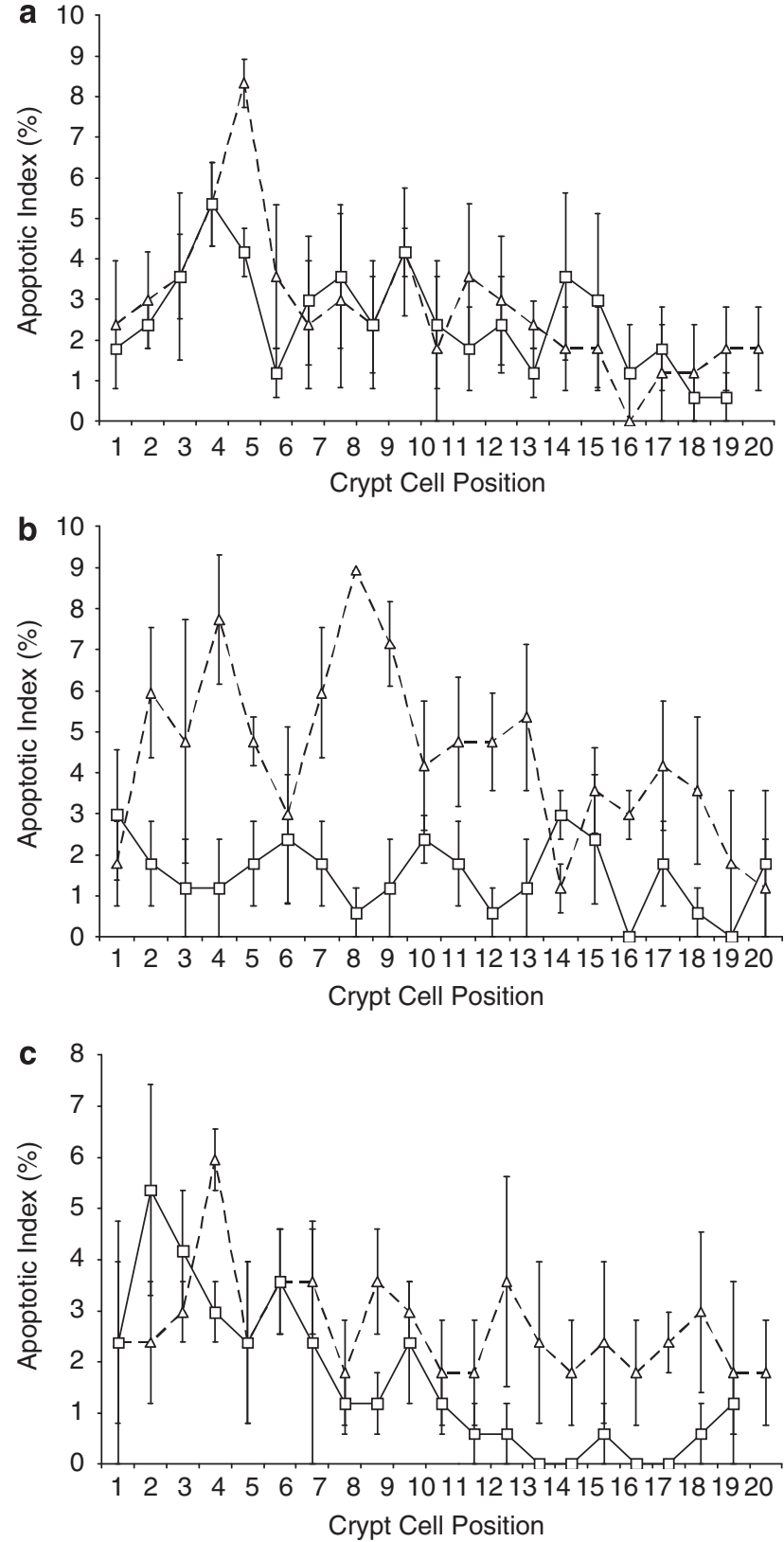

Figure 4 Changes in individual small-intestine crypt cell apoptotic indices in Stat ${ }^{\text {t/ }}$ - and Stat $3^{\text {wt } /-}$ crypts in response to induction of Cre recombinase expression. (a) Apoptotic indices for Stat ${ }^{\text {t/ }}{ }^{\text {(dashed line/triangles) and Stat }}{ }^{\mathrm{wt}-}$ (solid line/squares) crypts at individual crypt cell positions at 1.7 days after $\beta$-naphthoflavone injection/induction of Cre recombinase expression. (b) Apoptotic indices for Stat ${ }^{\text {fl/- }}$ (dashed line/triangles) and Stat3 ${ }^{\text {wt/- }}$ (solid line/squares) crypts at individual crypt cell positions at 2 days after $\beta$-naphthoflavone injection/induction of Cre recombinase expression. (c) Apoptotic indices for Stat $3^{f / /}$ (dashed line/ triangles) and Stat3 ${ }^{\text {wt/ }}$ (solid line/squares) crypts at individual crypt cell positions at 3 days after $\beta$-naphthoflavone injection/induction of Cre recombinase expression. The error bars indicate S.E.M. values, $N=3$ Stat $^{f t /-}$ versus 3 Stat ${ }^{\mathrm{wt} /-}$ mice per time point

crypt positions showing elevated apoptotic frequencies relative to control crypts had shifted to the upper half of the crypt (Figure 4c) - again consistent with the proliferation, migration and apoptosis of functionally STAT3-null crypt epithelial cells. 
Activation of caspase 3 correlates with loss of functional STAT3 in the crypt. To confirm the apoptotic index measurements, activated (cleaved) caspase 3 immunohistochemistry was performed on the small intestine. By day 2, there was an elevated frequency of activated caspase 3-positive cells in the Stat ${ }^{f l /}-$ smallintestine crypt versus the Stat ${ }^{w t /}$ - control (Figure 5a). When activated caspase 3-positive cell frequencies were assessed at individual crypt cell positions, there was a clear elevation in the Stat ${ }^{f l-}$ crypt relative to the Stat ${ }^{w t /-}$ in the central third of the crypt (Figure 5b). Further, the overall frequency of activated caspase 3-positive cells by 2 days after Cre induction was significantly higher (4.207 versus $2.37 \%$, $P=0.0404, N=3$ Stat $^{f / /}$ versus 3 Stat $^{w t /-}$ ) in the Stat $^{f l /-}$ versus Stat ${ }^{w t /-}$ crypts (Figure 5c). These activated caspase 3 frequencies were in reasonable agreement with the $\mathrm{H}+\mathrm{E}$-derived apoptotic indices presented earlier (Figure $3 a$ ), a representative $\mathrm{H}+\mathrm{E}$ stained apoptotic body is illustrated (Figure $5 d$ ).

Loss of bromodeoxyuridine-labelled long-term labelretaining cells at positions +4 to +6 in the Stat $3^{f /-}$ crypt following Cre induction. Long-lived label-retaining cells in small-intestine crypts were identified using a bromodeoxyuridine (BrdU)-labelling approach, allowing investigation of the requirement for functional STAT3 for long-term label-retaining crypt stem cell survival.

Following anti-BrdU immunohistochemistry, all well-formed crypts were counted, and those containing BrdU-positive nuclei identified. Subsequently, any BrdU-positive cells showing any trace of eosin-staining granules and a clear cytoplasm - that is any remaining labelled Paneth cells - were excluded. The remaining BrdU-positive cells were then assigned to the crypt base region (crypt positions +1 to +3 from the base), the crypt +4 to +6 region (Figure $6 a$ ), or to higher positions within the crypt. The highest frequency of long-term label-retaining cells was clearly located in the +4 to +6 region up from the Stat $3^{w t /}$ crypt base (Figure $6 b$ ) - as expected from previous studies of crypt stem cells/labelretaining cells. ${ }^{9}$ Interestingly, the only region showing any significant difference in the frequency of BrdU-positive nuclei between the Stat ${ }^{f l /}$ - and $S t a t 3^{w t /-}$ genotypes was the +4 to +6 region - with the frequency of BrdU-positive nuclei being much lower in the Stat ${ }^{f /-}$ crypts compared with Stat3 ${ }^{\text {wt } /-}$ crypts $\left(0.62\right.$ versus $1.85 \%, P=0.0404, N=3$ Stat $^{f / /}$ versus 3 Stat $\left.3^{w t /-}\right)$. Hence, functional STAT3 is required for crypt +4 to +6 region long-term label-retaining stem cell survival.

Transient appearance of the recombined Stat $3^{f l}$ allele. Given the transient appearance of LacZ activity around 2 days after Cre induction and the peak in Stat3 ${ }^{f /-}$ crypt apoptotic activity by 2 days after induction, it seemed likely that STAT3 inactivation resulted in the elimination of Cre-recombined Stat3 ${ }^{f / /}$ crypt stem cells. To confirm this, a quantitative polymerase chain reaction (Q-PCR) was performed on small-intestine DNA using a primer pair, which would amplify only the recombined Stat3 ${ }^{f l}$ allele. A control Q-PCR using primers specific for a distant region of all three Stat3 allele variants ensured that all reactions had equal amounts and integrity of template DNA.
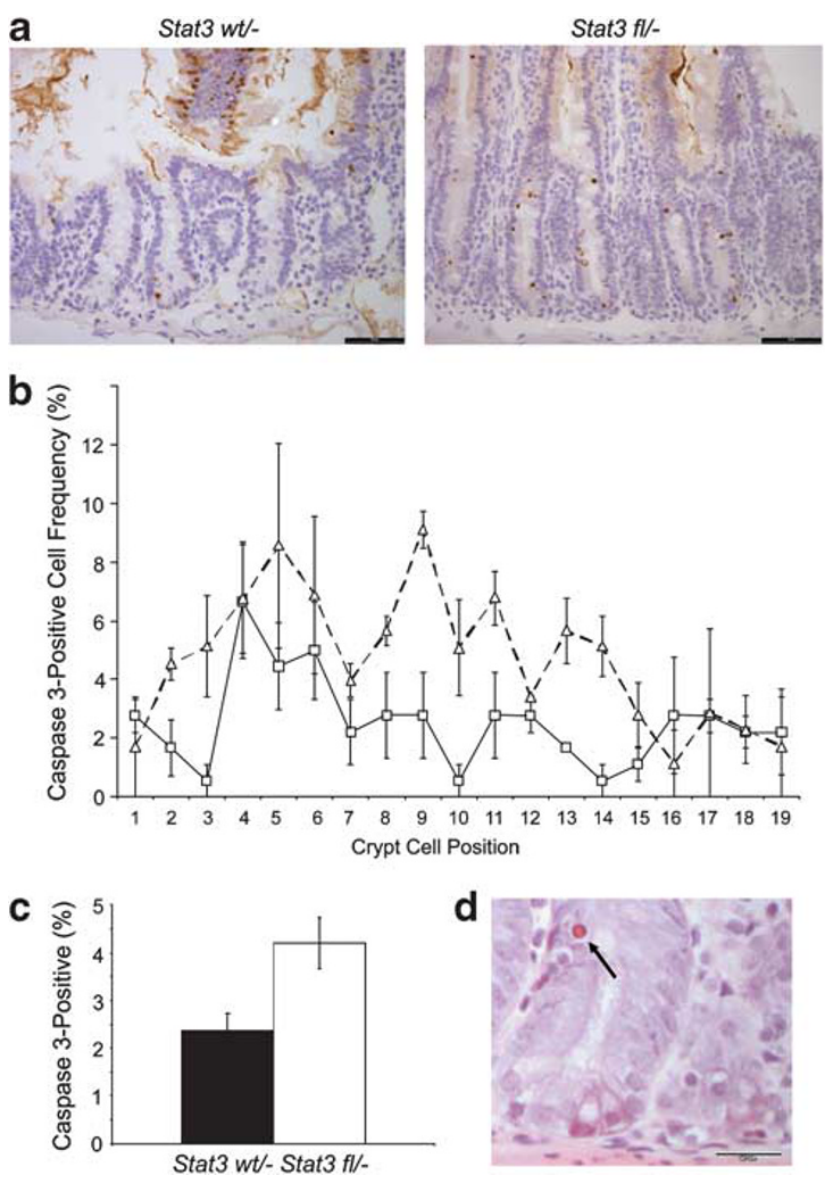

Figure 5 Correlation of elevated apoptotic indices in Stat $3^{f / /}$ crypts following induction of Cre recombinase expression with elevated activated (proteolytically cleaved) caspase 3 immunoreactivity. (a) Anti-activated caspase 3 immunoreactivity in $S t a t 3^{\text {wt }-}$ and Stat ${ }^{t /-}$ small-intestine crypts at 2 days after Cre induction, the black bars represent $50 \mu \mathrm{m}$. (b) Frequency of activated caspase 3 immunoreactive cells at individual crypt cell positions in Stat ${ }^{f / /}-$ (dashed line/triangles) versus

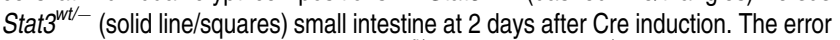
bars indicate S.E.M. values, $N=3$ Stat $3^{t / /}-$ versus 3 Stat $3^{\mathrm{wt}-}$ mice per time point. (c) Overall frequency of activated caspase 3 immunoreactive cells in Stat3 ${ }^{\text {wt }}$ - (solid bar) versus Stat3 $3^{\text {tl/- }}$ (open bar) small-intestine crypts at 2 days after Cre induction, error bars indicate S.E.M. values, $N=3$ Stat $^{\text {t/ } /-}$ versus 3 Stat $^{{ }^{\text {th }}-}$ mice. (d) Representative apoptotic body (arrowed) in Stat $3^{\text {t//- }}$ small-intestine crypt at 2 days after induction of Cre expression, the black bar represents $20 \mu \mathrm{m}$

With the control primer pair, $400 \mathrm{ng}$ of genomic DNA yielded low and essentially constant threshold cycle $(\mathrm{Ct})$ values of $\sim 21$ cycles for both the Stat $3^{f l /-}$ and Stat $3^{\text {wt/- }}$ small intestines before induction and over the time course of 1-4 days following Cre induction (Figure 7a). In contrast, the Ct values for the Q-PCR reaction detecting the recombined Stat ${ }^{f l}$ allele were initially very high in both the Stat $3^{f /-}$ and Stat3 ${ }^{\text {wt } /-}$ intestine DNA at $\sim 34$ cycles. Following Cre induction, the $\mathrm{Ct}$ values for the recombined $S t a t 3^{f l}$ allele reaction remained very high and fairly constant in the Stat ${ }^{w t /-}$ control intestine DNA at about 35 cycles throughout the time course. In contrast, in the Stat $^{f l /-}$ experimental intestine, the Ct values for the recombined Stat ${ }^{f l}$ Q-PCR decreases rapidly, reaching a minimum around 2 days after induction, after which the $\mathrm{Ct}$ values began increasing again towards the recombined Stat ${ }^{f l}$ allele Ct values seen in the Stat3 ${ }^{\text {wt/- }}$ control intestine Q-PCR 


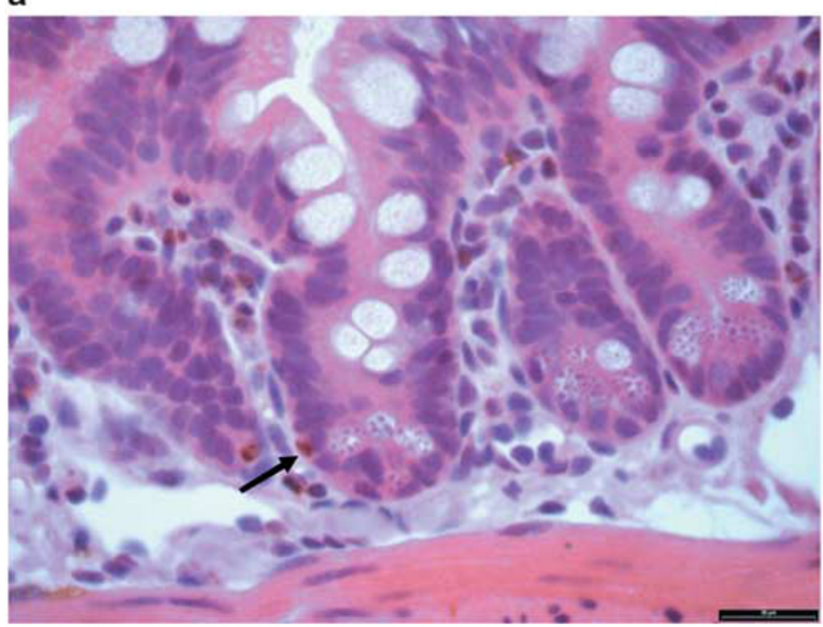

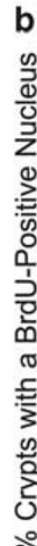

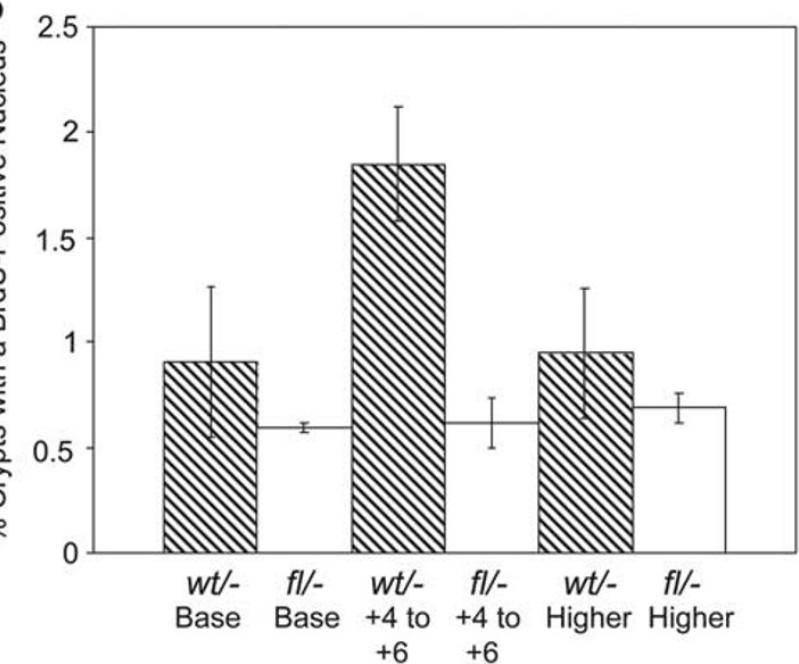

Figure 6 Long-term BrdU labelling of Stat ${ }^{f /-}$ and Stat $3^{\text {wt }}{ }^{\text {t/ }}$ small-intestine crypts demonstrating the loss of BrdU-labelled +4 to +6 crypt cells in response to STAT3 inactivation. Stat $3^{\text {t/ }}$ and Stat3 $3^{\text {wt/ }}$ mice were given BrdU in their drinking water for 3 weeks, followed by an 8-week water-only chase phase. This was followed by $\beta$-naphthoflavone injection and induction of Cre recombinase expression with a 7 day delay before harvesting. Small-intestine samples were then analysed by anti-BrdU immunohistochemistry and all BrdU-positive, nonPaneth, nuclei identified. The BrdU-positive cells were then divided up into three groups - crypt base positions +1 to +3 (base), the +4 to +6 positions ( +4 to +6 ) and crypt positions from +7 to the crypt-villus junction (higher). (a) Anti-BrdU immunohistochemistry of a (Stat3 ${ }^{\text {wt- }}$ ) crypt demonstrating a representative BrdUpositive nucleus (arrowed) in the +4 to +6 crypt position range, the black bar represents $20 \mu \mathrm{m}$. (b) Frequency of crypts retaining a BrdU-positive nucleus at the crypt base, +4 to +6 and higher positions, Stat $3^{\text {wt }-}$ crypts are represented by hatched bars, whereas Stat ${ }^{t / /}$ crypts are represented by open bars. The error bars indicate S.E.M. values, $N=3$ Stat $^{\text {t/ } /-}$ versus 3 Stat $3^{\text {wt }-}$ mice

(Figure 7a) - behaviour consistent with the transient appearance and disappearance of the recombined Stat ${ }^{f l}$ allele in the Stat ${ }^{f / /}$ - small intestine.

Relating the recombined Stat $^{f l}$ and control Stat3Q-PCR Ct values from Stat3 $3^{f /-}$ and Stat3 ${ }^{\text {wt/- }}$ intestine DNA, normalising to un-induced (day 0 ) values and raising the output value to $2^{\mathrm{x}}$ allowed a relative recombined $S t a t 3^{f l}$ allele level to be plotted linearly. This approach revealed a dramatic rise and fall in the relative level of the recombined $S t a t 3^{f l}$ allele in the Stat ${ }^{f l /}$ a
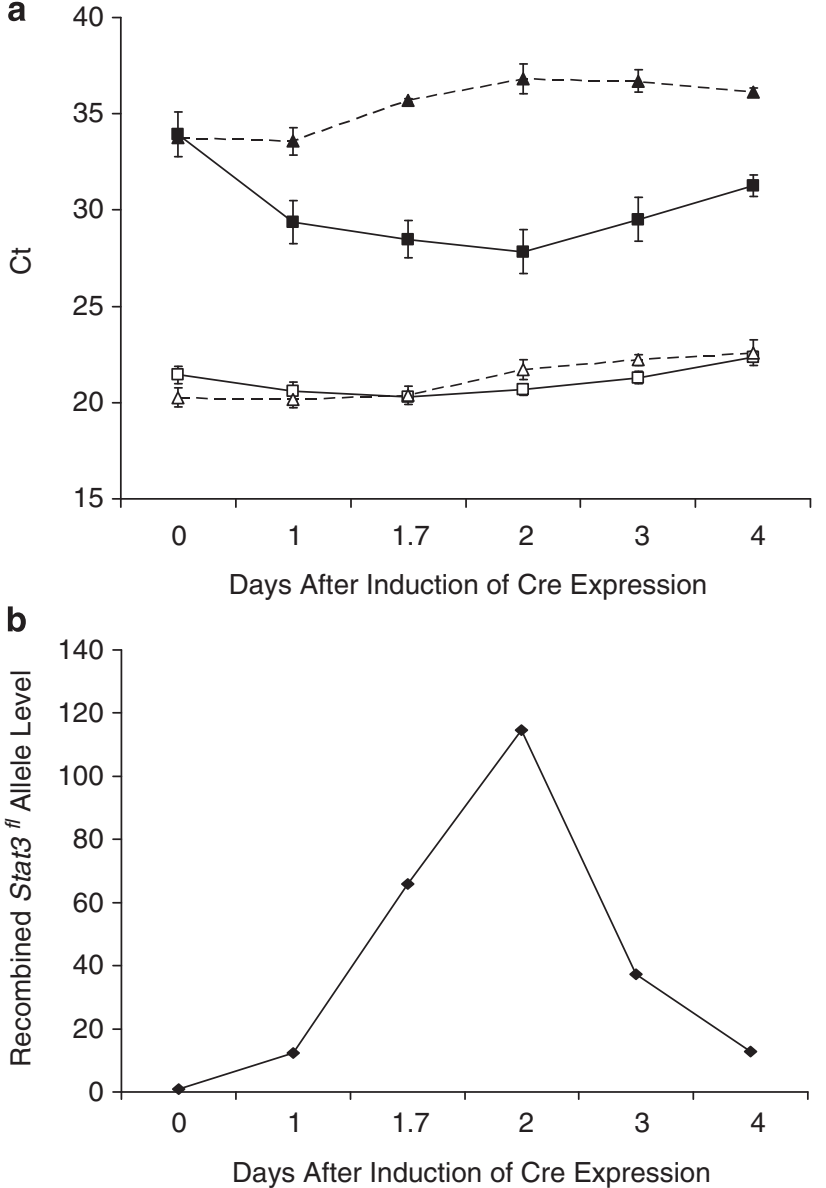

Figure 7 Q-PCR demonstrating the transient appearance and disappearance of the recombined Stat $3^{\text {fl }}$ allele. (a) Ct values (cycles) were plotted versus time after induction of Cre expression for the recombined Stat $3^{f l}$ allele Q-PCR reaction using Stat ${ }^{t / /}-$ small-intestine genomic DNA (solid line, solid squares) and for the recombined Stat3 ${ }^{f l}$ allele Q-PCR reaction using Stat3 ${ }^{\text {wt }}$ - small-intestine genomic DNA (dashed line, solid triangles). Ct values were also plotted versus time after induction of Cre expression for the control Stat3 (wt/fl/- alleles) Q-PCR reaction using Stat $3^{\text {th/- }}$ small-intestine genomic DNA (solid line, open squares) and for the control Q-PCR reaction using Stat3 ${ }^{\text {wt }-}$ small-intestine genomic DNA (dashed line, open triangles). The error bars indicate S.E.M. values, $N=3$ Stat $3^{\text {t/l- }}$ versus 3 Stat3 ${ }^{\text {wt }-}$ mice per time point. (b) Q-PCR Ct values for the recombined Stat $3^{\text {tl }}$ allele reaction versus time after induction of Cre expression were then converted into relative, linear-scaled, values for the level of the recombined Stat ${ }^{f l}$ allele. This involved subtracting the average control Stat3 Q-PCR Ct value from the average recombined Stat $3^{f l} \mathrm{Q}-\mathrm{PCR} \mathrm{Ct}$ value to yield a difference value (difference). The uninduced (day 0) time point difference value from Stat3 ${ }^{\text {wt }}{ }^{-}$intestine genomic DNA was then normalised to the $S t a t 3^{f /-}$ intestine genomic DNA difference value to give a normalised difference value (normalised difference). Then the Stat $3^{f / /}-$ difference values were subtracted from the $S t a t 3^{\text {wt }}-$ normalised difference values to yield the difference of these difference values (difference of difference). Finally, the difference of difference values were raised to $2^{x}$ to yield a relative measure of the recombined Stat $3^{f l}$ allele, which could be plotted directly on a linear scale (no error bars are provided). $N=3$ Stat $3^{\text {t//- }}$ versus 3 Stat $3^{\text {wt/- }}$ mice per time point

versus the Stat3 ${ }^{w t /-}$ intestine, peaking at around 2 days after Cre induction (Figure 7b).

Elevated c-Myc and p53 expression implicated in the apoptotic removal of Cre-recombined Stat3 ${ }^{f / /}$ crypt cells. We also demonstrate statistically significantly 
a
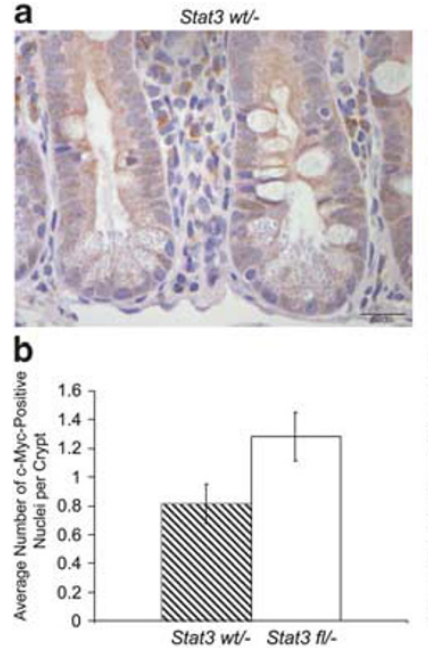

Figure 8 Upregulation of c-Myc expression in Stat3 ${ }^{f /-}$ relative to Stat3 ${ }^{\mathrm{wt}-}$ crypts at day 0.5 after induction of Cre expression as a potential mechanism for nonrecombined Stat $3^{\text {th/ }}$ cells to trigger p53-mediated apoptosis in Cre-recombined Stat $^{\text {t//- }}$ cells. (a) Anti-c-Myc immunohistochemistry in Stat $3^{\text {tl/- }}$ versus Stat ${ }^{\text {wt/- }}$ crypts at day 0.5 after induction of Cre expression. Immunohistochemistry panels are representative of three Stat ${ }^{t / /}$ versus three Stat3 ${ }^{\text {wt }}$ - mice, the black bars represent $20 \mu \mathrm{m}$. (b) Statistically significant increase in numbers of c-Myc-positive nuclei in Stat $3^{f /-}$ (open bar) versus Stat3 ${ }^{\mathrm{wt} /}$ - (hatched bar) crypts at day 0.5 after induction of Cre expression $(P=0.0404)$, the error bars indicate S.E.M. values, $N=3$ Stat3 $^{t / /}$ versus 3 Stat3 ${ }^{\text {wt } /-}$ mice. (c) Quantitation of anti-p53 immunohistochemistry demonstrating a statistically significant increase in the frequency of p53positive cell nuclei in Stat $3^{t / /}$ (open bars) relative to Stat ${ }^{\text {wt/- }}$ (hatched bars) crypts at 2 days $\left(P=0.0259, N=4\right.$ Stat $^{t / /}-$ versus 3 Stat $3^{\text {wt }-}$ mice $)$ and 3 days ( $P=0.0259$ or 0.0249 adjusted for ties), $N=4$ Stat $^{t / /-}$ versus 3 Stat ${ }^{\mathrm{wt} /}$ - mice) after induction of Cre expression

$\left(P=0.0404, \quad N=3\right.$ Stat $^{f l /-}$ versus 3 Stat $\left.^{w t /-}\right)$ elevated C-Myc expression (1.283 versus 0.816 positive nuclei per crypt) in Stat ${ }^{f / /}$ relative to Stat $3^{\text {wt/- }}$ crypts at 0.5 days after Cre induction (Figures $8 a$ and b). STAT3-driven c-Myc expression $^{17}$ in non-recombined Stat $^{f l /-}$ crypt cells could trigger apoptosis in Cre-recombined Stat $3^{f / /}$ cells through a cellular competition mechanism, ${ }^{18}$ accelerating crypt repopulation with stem cells retaining a functional Stat ${ }^{f l}$ allele. The apoptotic mechanism triggered in the recombined Stat ${ }^{f l /}$ - cells may be $\mathrm{p} 53$ mediated as the frequency of p53positive crypt nuclei is significantly elevated in Stat ${ }^{f / L}$ crypts relative to Stat ${ }^{w t /-}$ crypts at 2 days $(2.169$ versus $0.492 \%$, $P=0.0259, N=4$ Stat $^{f l /-}$ versus 3 Stat $^{\text {wt } /-}$ ) and 3 days (2.204 versus $0.335 \%, P=0.0259$ or $P=0.0249$ adjusted for ties, $N=4$ Stat $^{f / /}$ versus 3 Stat $^{w t /-}$ ) after Cre induction (Figure 8c).

\section{Caspase 3 activation in STAT3-depleted Cre-recombined} Stat $3^{f / /}$ crypt epithelial cells. To directly demonstrate that STAT3 inactivation in a crypt epithelial cell can lead to the apoptosis of that cell, we performed confocal fluorescent immunohistochemistry on serial small-intestine tissue sections using an anti-activated caspase 3 antibody combined with a 4',6-diamidino-2-phenylindole (DAPI) nuclear counterstain versus, on alternating slides, the NEB/ CST \#9132 anti-STAT3 antibody, again combined with a

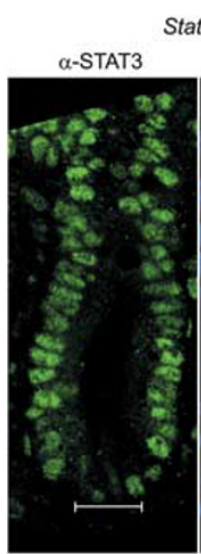

$\alpha-$ CL.CASP.3
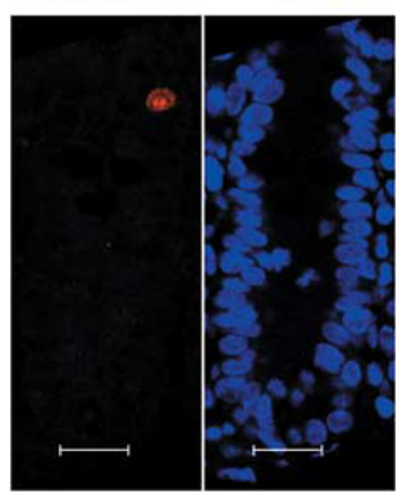

DAPI

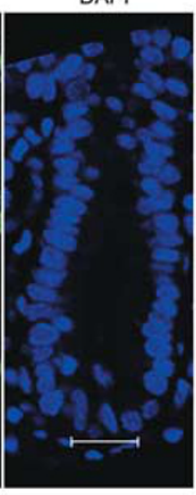

DAPI
Figure 9 Confocal fluorescence immunohistochemistry demonstrating activation of caspase 3 cleavage in a Stat $3^{f /-}$ crypt at 2 days after induction of Cre expression and its correlation with loss of STAT3 immunoreactivity in corresponding cells identified (arrowed) on the subsequent serial tissue section. The white scale bars represent $20 \mu \mathrm{m}$

DAPI counterstain. This demonstrated the presence in day 2 Cre-recombined Stat ${ }^{f / /}$ crypts of epithelial cells, which showed essentially no detectable STAT3 but which displayed clear activated caspase 3 immunoreactivity (Figure 9).

Elevated Bmi1 in the recombined Stat $3^{f l /}$ crypt as a possible mechanism to accelerate crypt repopulation. It has been suggested that the polycomb transcriptional repressor family member Bmi1 marks the small-intestine crypt +4 to +6 region stem cell, with expression at the +4 and +5 positions up from the crypt base. ${ }^{19}$ Hence, we performed anti-Bmi1 immunohistochemistry on Stat ${ }^{f l /}$ and Stat3 $^{w t /-}$ small intestine. In contrast to the expected obvious Bmi1 immunoreactivity at the +4 and +5 positions in Stat $3^{w t /}$ crypts, there was a generally very low frequency of Bmi1-positive nuclei, which were usually found in the lower half of the crypt. In contrast, there was a very obvious significant increase in the frequency of strongly Bmi1-positive nuclei throughout the crypt in $S t a t 3^{f l /}$ - relative to $S t a t 3^{\mathrm{wt} /-}$ crypts at 2 days (10.85 versus $3.39 \%)$ and 3 days $(28.81$ versus $1.02 \%)$ after Cre induction $\left(P=0.0404, N=3\right.$ Stat ${ }^{f / /}$

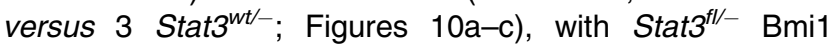
immunoreactivity reverting to control values by 4 days after Cre induction. 


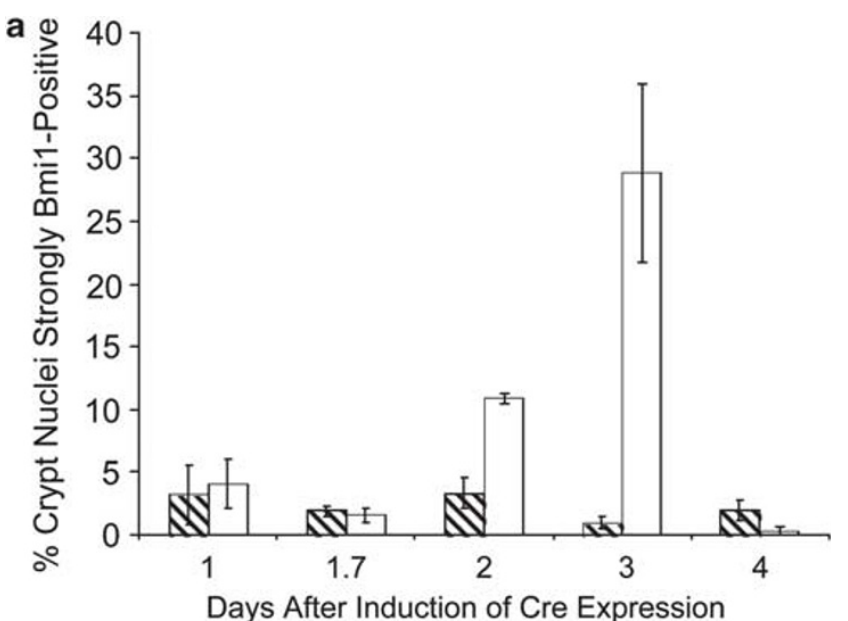

b

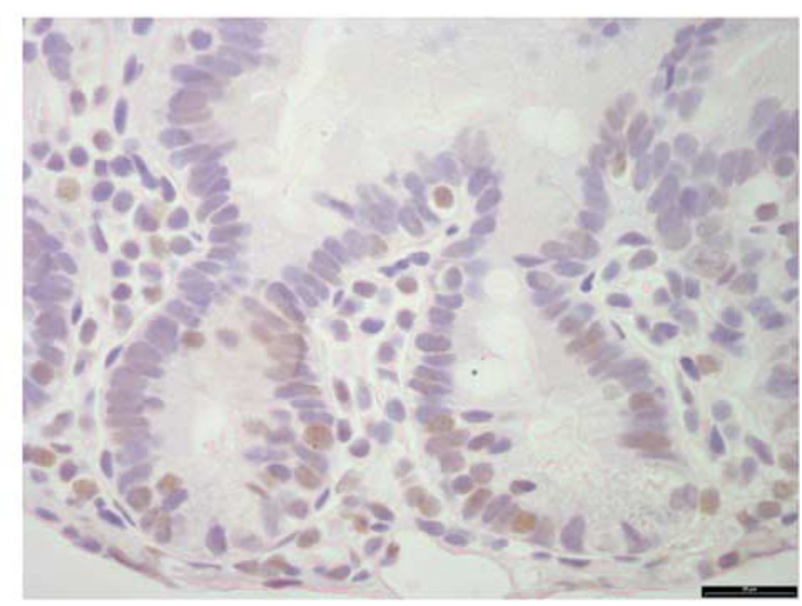

C

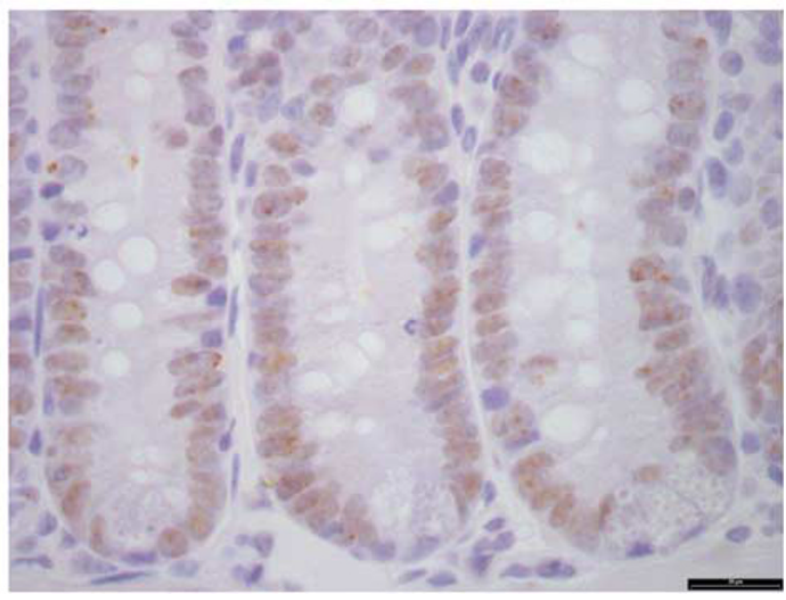

Figure 10 Quantitation of a transient peak in Bmi1 expression in Stat3 ${ }^{f / /}$ crypts following $\beta$-naphthoflavone injection and induction of Cre expression. (a) Stat3 $3^{f / /}$ and Stat $3^{\text {wt }}$ - small intestines were subjected to anti-Bmi1 immunohistochemistry. Strongly anti-Bmi1 immunoreactive crypt nuclei were counted and the average percentage of strongly positive nuclei in Stat3 ${ }^{\text {wt/- }}$ (hatched bars) and Stat ${ }^{t / /}{ }^{t /}$ (open bars) crypts charted. The error bars indicate S.E.M. values, $N=3$ Stat $^{t / /}-$ versus 3 Stat3 ${ }^{\text {wt } / \text { - }}$ mice per time point. (b) Anti-Bmi1 immunohistochemistry from a Stat3 ${ }^{\text {tt }-}$ small intestine at 3 days after induction of Cre expression. The immunohistochemistry panel is representative of three Stat3 ${ }^{\text {wt/ }}$ mice, the black bar represents $20 \mu \mathrm{m}$. (c) Anti-Bmi1 immunohistochemistry from a Stat $3^{\text {ti/- }}$ small intestine at 3 days after induction of Cre expression. The immunohistochemistry panel is representative of three Stat ${ }^{t / /}-$ mice, the black bar represents $20 \mu \mathrm{m}$
It might be difficult to reconcile massively increased Bmi1 expression with a role as a robust marker of the crypt +4 to +6 region stem cell. Others have suggested that elevated Bmi1 expression (at least in murine ES cells) is rather a marker of differentiation and associated with exit from the selfrenewing/pluripotent state. ${ }^{20}$ Elevated Bmi1 expression on exiting the self-renewing state in murine ES cells might also occur in recombined Stat $3^{f /-}$ crypt stem cells, hastening crypt repopulation with stem cells retaining a functional Stat ${ }^{f l}$ allele.

\section{Discussion}

This study demonstrates the requirement for functional STAT3 in the crypt stem cells of the murine small intestine, with recombined $S t a t 3^{f /-}$ crypt stem cells being rapidly eliminated and the intestinal epithelium being repopulated with cells retaining functional STAT3.

The $\mathrm{AH}$-Cre transgene allows Cre expression in both smallintestine crypt stem cell compartments - the +4 to +6 position long-term label-retaining master stem cells, and the proliferating, non-label-retaining, $\mathrm{Lgr}^{+} \mathrm{CBC}$ stem cells driving tissue homeostasis. The +5 to +6 location of the initial burst of apoptosis seen in the Stat $3^{f /-}$ crypt relative to the Stat $3^{\text {wt }}$ - crypt at day 1.7 following induction of Cre expression corresponds well with the location of the +4 to +6 label-retaining quiescent master stem cell. Whereas by day 2 following Cre induction, the elevated apoptotic index in the Stat ${ }^{f /-}$ crypt is also clear at lower positions in the crypt. This might reflect two separate events - an initial recombination-driven apoptotic pulse by day 1.7 in the $S t a t 3^{f /-}+4$ to +6 master stem cells, followed at around day 2 by a wave of functionally STAT3-null cells generated from the recombined Stat ${ }^{f / /}-$ Lgr5 $^{+}$CBC cells moving up the crypt and undergoing apoptosis. The rapid removal of Cre-recombined Stat ${ }^{f / /}$ cells might involve STAT3-driven c-Myc expression ${ }^{17}$ and cellular competition ${ }^{18}$ whereby non-recombined Stat $3^{f / /}$ cells could trigger p53-dependent apoptosis in Cre-recombined $S t a t 3^{f l /-}$ cells. The upregulated c-Myc expression in Stat ${ }^{f / /}$ versus Stat $^{\text {wt/- }}$ crypts at day 0.5 and the upregulated p53 expression in Stat $3^{f / /}$ crypts at days 2 and 3 following Cre induction could support such a mechanism. Further, confocal fluorescence microscopy experiments suggested that the loss of functional STAT3 in recombined Stat ${ }^{\text {fl/ }-}$ crypts sensitises cells to caspase 3-driven apoptosis.

The failure to observe obvious anti-Bmi1 immunoreactivity at the +4 and +5 positions in the Stat $3^{w t /-}$ crypt base (in the expectation of reduced immunoreactivity following Stat ${ }^{f / /}$ crypt recombination) was unexpected. Instead, there was a massive upregulation of strong anti-Bmi1 immunoreactivity in the Stat $3^{f /-}$ crypt at 2-3 days following Cre induction.

One explanation for the upregulated crypt Bmi1 expression following STAT3 inactivation might lie in a recent study of a murine ES cell chromatin remodelling complex, esBAF, critical for maintaining ES cell pluripotency and self-renewal. ${ }^{20}$ Chromatin immunoprecipitation-sequencing demonstrated a highly statistically significant $70 \%$ co-occupation of murine ES cell target genes by both STAT3 and the esBAF ATPase component Brg. ${ }^{20}$ 
Further, knocking-down Brg expression upregulated the expression of several polycomb group (PcG) genes including Bmi1, Cbx7 and Ring1a - which normally contribute to the polycomb repressive complex 1 . These genes also contained a statistically significant region bound by $\mathrm{Brg}$, with the suggestion that esBAF/Brg normally antagonises PcG function in murine ES cells by binding to and repressing $P c G$ gene transcription. In a striking parallel with Brg knockdown in murine ES cells, STAT3 inactivation in the small-intestine crypt also upregulated Bmi1 expression, implying that the frequent co-occupation of murine ES cell target genes by STAT3 and esBAF/Brg is functionally important - with a potentially analogous interaction in the crypt stem cell(s).

In contrast, several PcG subunit genes were not upregulated following Brg knockdown, these included Suz12, Eed and Ezh2, encoding Polycomb repressive complex 2 components. ${ }^{20}$ Interestingly, the Eed gene is transcriptionally controlled by STAT3 (and Oct4) in murine ES cells, with STAT3/Oct4 (via Eed) reversibly silencing differentiationassociated genes such as Tbx5, GATA6 and $C d \times 2 .{ }^{21}$ Further, Eed and Bmi1 can function antagonistically - in haematopoietic cell proliferation, Eed demonstrated an anti-proliferative function, negatively regulating lymphoid and myeloid progenitor cell numbers in the bone marrow, ${ }^{22}$ whereas Bmi1 positively regulated primitive bone marrow progenitor cell proliferation. $^{22}$

Thus, one model for STAT3 function in the murine smallintestine crypt stem cell(s) could involve an interaction between STAT3 and a stem cell chromatin remodelling complex to bind to the Bmi1 gene, suppressing Bmi1 expression and restraining crypt stem cell proliferation. In addition, STAT3 could drive Eed gene expression, again downregulating crypt stem cell proliferation. STAT3 inactivation would impair both of these potential mechanisms to restrain crypt stem cell proliferation. The STAT3-null crypt stem cells would then exit the pluripotent/self-renewing state, proliferate, and be removed through apoptosis, accelerating the repopulation of the recombined Stat $3^{f /-}$ small intestine.

\footnotetext{
Materials and Methods

Generation of mouse strains. Mice carrying the Floxed(f) and Null(-) Stat3 alleles were the kind gift of Professor S Akira, ${ }^{14,16}$ whereas mice carrying the $A H$-Cre transgene were the kind gift of Dr. DJ Winton. ${ }^{13}$ Mice used in this study were outbred, segregating for the C57BL6/J 129/Ola and C3H genomes, with littermates being used as controls. Murine genomic DNA was isolated using a commercial DNA purification kit (5 Prime GmbH, Hamburg, Germany) and genotyped by PCR using primers which are specific for the Stat3 ${ }^{\mathrm{wt}}$ versus ${ }^{\mathrm{fl}}$ alleles, for the Stat3 ${ }^{-}$allele and the Cre and LacZ transgenes. The following oligodeoxynucleotide primer pairs were used for PCR genotyping: $5^{\prime}$-CCTGAAGACCAAGTTCATCTGTGTGAC- $3^{\prime}$ and $5^{\prime}$-CA CACAAGCCATCAAACTCTGGTCTCC- $3^{\prime}$ yields an $\sim 320$-bp PCR product for the Stat $3^{f l}$ allele versus an $\sim 230$-bp PCR product for the Stat3 $3^{\text {wt }}$ allele. For the Stat3 Null(-) allele PCR reaction, primers $5^{\prime}$-AGCAGCTGACAACGCTGGCTGAGAAG CT- $3^{\prime}$ and $5^{\prime}$-ATCGCCTTCTATCGCCTTCTTGACGA- $3^{\prime}$ yield an $\sim 1$-kbp PCR product. For the combined PCR reaction for Cre and LacZ transgenes, the $5^{\prime}$-TGA CCGTACACCAAAATTTG- $3^{\prime}$ and $5^{\prime}$-ATTGCCCCTGTTTCACTATC- $3^{\prime}$ primer pair yields an $\sim 1-\mathrm{kbp}$ PCR product for the Cre transgene and the $5^{\prime}$-CTGGCGTTAC CCAACTTAAT- $3^{\prime}$ and $5^{\prime}$-ATAACTGCCGTCACTCCAAC-3' primer pair yields an $\sim 500$-bp PCR product for the LacZ transgene. All mice used in this study were male, between 3 and 6 months old (with the exception of Supplementary Figure S1), with three or more mice per time point for both genotypes, and were cared for in accordance with UK Home Office guidelines.
}

Induction of recombination and harvesting experimental and control mice. To induce Cre recombinase expression, male mice were injected intraperitoneally with a $10 \mathrm{mg} / \mathrm{ml} \beta$-naphthoflavone (Sigma, St. Louis, MO, USA) solution in corn oil (Sigma) to give a final $\beta$-naphthoflavone dose of $100 \mathrm{mg} \mathrm{per} \mathrm{kg}$ body weight. Three intraperitoneal injections were administered in 1 day with injections spaced $2 \mathrm{~h}$ apart for the $1,1.7$ and 2 day time points and $3-4 \mathrm{~h}$ apart for the 3 and 4 day time points, all mice were harvested in the afternoon. After harvesting, the first $8 \mathrm{~cm}$ of small intestine and the final remaining bulk part of the small intestine were transferred into methacarn fixative $(4: 2: 1$ volumes methanol:chloroform: glacial acetic acid) overnight before transfer to neutralbuffered formalin (Sigma) and tissue processing. The intervening section of small intestine was divided into samples for overnight fixation in cold formalin and paraffin embedding for immunohistochemistry (quick fixed), and for genomic DNA extraction.

Long-term BrdU label-retention experiment. For long-term BrdU labelretention experiments, mice were given BrdU (Sigma) dissolved in their drinking water at $3 \mathrm{mg} / \mathrm{ml}$ for 3 weeks, followed by an 8 week chase period with water alone. Mice were then given three $100 \mathrm{mg} / \mathrm{kg} \beta$-naphthoflavone (in corn oil) intraperitoneal injections $4 \mathrm{~h}$ apart to induce Cre recombinase expression and harvested 7 days later. Following harvesting, small-intestine samples were quick fixed and then subjected to anti-BrdU immunohistochemistry, brief haematoxylin counterstaining and extended eosin staining. All well-formed crypts were counted and any nuclei showing BrdU immunoreactivity were identified, with any BrdU-positive cells showing histochemical or morphological features of Paneth cells being discounted.

LacZ staining of small intestine. For LacZ staining, small intestines were harvested, flushed through with ice-cold phosphate-buffered saline (PBS; Invitrogen, Carlsbad, CA, USA) and then flushed through with ice-cold X-gal fixative solution ( 0.5 volumes formalin, 0.5 volumes PBS, 0.004 volumes $25 \%$ glutaraldehyde (wt/vol) (Sigma) solution). Sections of small intestine were then cut open, pinned flat and lumen-uppermost on a paraffin wax-filled Petri dish and fixed for $1 \mathrm{~h}$ in X-gal fixative, then washed with PBS and incubated with demucifying solution (10\% (vol/vol) glycerol, $10 \mathrm{mM}$ Tris- $\mathrm{HCl}$ pH8.2, 20\% (vol/vol) ethanol, $92 \mathrm{mM} \mathrm{NaCl}, 22 \mathrm{mM}$ dithiothreitol) for $1 \mathrm{~h}$. Subsequently, the intestine was washed with PBS and any adhering mucus removed. The dish was then incubated overnight in the dark with gentle agitation with X-gal staining solution ( 0.004 volumes of $5 \%$ (wt/vol) X-gal in dimethylformamide (Promega, Madison, WI, USA) in $10 \mathrm{mM} \mathrm{MgCl}_{2}$, $29 \mathrm{mM}$ potassium ferricyanide, $30 \mathrm{mM}$ potassium ferrocyanide in PBS). Finally, the X-gal staining solution was discarded and the intestine washed with PBS and formalin.

Measurements of apoptotic and mitotic indices in murine small intestine. For measurements of apoptotic and mitotic indices in the crypts of the small intestine, methacarn-fixed small-intestine slides were stained with $\mathrm{H}+\mathrm{E}$ (RA Lamb, Thermofisher Scientific, Waltham, MA, USA). Apoptotic and mitotic cells were identified by their characteristic morphologies with each individual cell position within 56 half-crypts being assessed and counted to yield apoptotic and mitotic indices at each individual position within the crypt. These individual crypt position frequencies were then summed to yield overall crypt apoptotic and mitotic indices.

Immunohistochemistry. STAT3 immunohistochemistry used a primary antibody (NEB/CST \#9132) recognising an epitope close to the STAT3 tyrosine 705 residue. Antigen retrieval used heating slides in $1 \times$ citrate buffer (LabVision, Thermofisher Scientific). The primary rabbit anti-STAT3 antibody NEB/CST \#9132 was diluted 1:100 in 5\% normal goat serum (NGS (vol/vol); Dako, Glostrup, Denmark) in $1 \times$ Tris-buffered saline (TBS; Sigma). The secondary antibody step used anti-rabbit horseradish peroxidase (HRP)-labelled polymer (EnVision ${ }^{+}$, Dako). HRP activity was then visualised with a $3,3^{\prime}$-diaminobenzidine (DAB) chromogenic substrate system (EnVision ${ }^{+}$, Dako), DAB staining used a 10 min development time.

STAT3 phosphotyrosine 705 immunohistochemistry used the NEB/CST \#9131 primary antibody. Antigen retrieval used heating slides in $1 \times$ EDTA buffer (LabVision). The primary rabbit anti-phosphotyrosine 705 STAT3 antibody (NEB/ CST \#9131) was diluted 1:100 in 5\% NGS (vol/vol) in $1 \times$ TBS, $0.1 \%$ (vol/vol) Tween-20 (Sigma; TBS/T). The secondary antibody step used anti-rabbit HRPlabelled polymer (EnVision ${ }^{+}$, Dako), DAB (Dako) staining used a $10 \mathrm{~min}$ development time. 
Activated (cleaved) caspase 3 immunohistochemistry used antigen retrieval with slides heated in $1 \times$ EDTA buffer (LabVision), the rabbit monoclonal anti-activated caspase 3 primary antibody (NEB/CST \#9664) was diluted 1:200 in 5\% NGS (Dako) (vol/vol) in $1 \times$ TBS/T (Sigma). The secondary antibody step used an anti-rabbit HRP-labelled polymer (EnVision ${ }^{+}$, Dako). DAB (Dako) staining used a 15 min development time.

BrdU immunohistochemistry/eosin staining for the long-term label-retention experiment used antigen retrieval by heating slides in $1 \times$ citrate buffer (LabVision). The mouse anti-BrdU primary antibody (Becton Dickinson \#347580, San Diego, CA, USA) was diluted $1: 250$ in $10 \% \mathrm{NGS}$ (vol/vol) in $1 \times \mathrm{TBS} / \mathrm{T}$. The secondary antibody step used an anti-mouse HRP-labelled polymer (EnVision ${ }^{+}$, Dako). DAB (Dako) staining used a 40 min development time. Following counterstaining in haematoxylin for $20 \mathrm{~s}$ and washing, slides were stained in eosin for $8 \mathrm{~min}$ to identify Paneth cells, then briefly washed, dehydrated and mounted.

c-Myc immunohistochemistry used antigen retrieval with slides heated in $1 \times$ citrate buffer (LabVision). The rabbit anti-c-Myc primary antibody (sc-788; Santa Cruz Biotechnology, Santa Cruz, CA, USA) was diluted 1: 100 in TBS/T, with an anti-rabbit HRP-labelled polymer (EnVision ${ }^{+}$, Dako) secondary antibody step and a 30 min DAB (Dako) staining development time.

Bmi1 immunohistochemistry used antigen retrieval with slides heated in $1 \times$ EDTA buffer (LabVision). The rabbit anti-Bmi1 primary antibody (NEB/CST \#2830) was diluted 1:100 in 10\% NGS (vol/vol) in TBS/T. The secondary antibody step used anti-rabbit HRP-labelled polymer (EnVision ${ }^{+}$, Dako). DAB (Dako) staining used a 15 min development time.

Quantitative polymerase chain reaction assay for recombined Stat3 $^{f l}$ allele. Q-PCR assays to determine the level of the recombined Stat ${ }^{f l}$ allele were carried out on genomic DNA prepared from small-intestine tissue samples using a QIAamp DNA Mini kit (Qiagen, Hilden, Germany) and performed using a StepOne Plus real-time PCR system (Applied Biosystems, Carlsbad, CA USA). For each genotype/time point, Q-PCR reactions were performed on smallintestine genomic DNA from three independent mice, with each $20 \mu \mathrm{l}$ reaction containing $400 \mathrm{ng}$ of template DNA, an oligodeoxynucleotide primer pair at a concentration of $1.25 \mu \mathrm{M}$ each and $1 \times$ SYBR Green and $1 \times$ ROX passive reference dye (Dynamo, Finnzymes, Espoo, Finland). To detect the recombined Stat $3^{f l}$ allele, a primer pair was designed with a coding sense primer hybridising close to the start of intron 21-22 (5'-TTCTCCAGTCAGTGGGTTCCA-3') and a noncoding sense primer hybridising beyond the Hindlll restriction site in intron 22-23 (5'-AGGGCCAGGTTGACAAGACAC-3') - which yielded a single Q-PCR product of $\sim 250$ bp in the presence of the recombined Stat $3^{f l}$ allele, but did not yield any product with the non-recombined Stat3 ${ }^{\text {fl }}$ allele, nor with the Stat $3^{\text {wt }}$ or Stat $3^{-}$alleles. As controls, Q-PCR reactions were performed using a primer pair, which hybridised with a distant region of all three Stat3 alleles. A coding sense primer hybridising near the $5^{\prime}$-end of Stat3 exon 5 (5'-GGCCAGGCCAACCACCCAAC- $\left.3^{\prime}\right)$ and a non-coding sense primer hybridising near the $3^{\prime}$-end of intron 5-6 (5'-AACACAGGTTACCTT TGGGA-3') yielded a single Q-PCR product of $\sim 230 \mathrm{bp}$ with all three Stat3 alleles. To amplify the recombined Stat3 ${ }^{\text {ft }}$ product, the following Q-PCR programme was used: $95^{\circ} \mathrm{C}$ for $10 \mathrm{~min}, 95^{\circ} \mathrm{C}$ for $15 \mathrm{~s}, 65^{\circ} \mathrm{C}$ for $1 \mathrm{~min}$, repeated for $40 \mathrm{cycles}$, and finally $95^{\circ} \mathrm{C}$ for $15 \mathrm{~s}$. To amplify the control total Stat 3 product, the following programme was used: $95^{\circ} \mathrm{C}$ for $10 \mathrm{~min}, 95^{\circ} \mathrm{C}$ for $15 \mathrm{~s}, 60^{\circ} \mathrm{C}$ for $1 \mathrm{~min}$, repeated for $40 \mathrm{cycles}$.

Confocal fluorescence immunohistochemical analysis of murine small intestine. Confocal fluorescence microscopy was performed using a Leica (Heidelberg, Germany) TCS SP2 AOBS spectral confocal microscope using a $\times 63$ oilimmersion objective and analysed using proprietary Leica confocal software. Serial small-intestine tissue section slides were stained for either STAT3 or activated caspase 3. Anti-STAT3 fluorescence immunohistochemistry used antigen retrieval by heating slides in $1 \times$ citrate buffer (LabVision). The anti-STAT3 NEB/CST \#9132 rabbit primary antibody was used at a 1:100 dilution in 5\% (vol/vol) NGS in TBS/T. The secondary antibody step used an Alexa 488-conjugated goat anti-rabbit reagent (Invitrogen) at a $1: 400$ dilution in TBS/T, with coverslips eventually mounted using Vectashield Hard-Set aqueous mounting medium containing DAPI (Vector, Burlingame, CA, USA). Anti-activated caspase 3 fluorescence immunohistochemistry used antigen retrieval by heating slides in $1 \times$ EDTA buffer (LabVision). The anti-activated caspase 3 NEB/ CST \#9661 rabbit primary antibody was used at a 1: 100 dilution in $5 \%$ (vol/vol) NGS in TBS/T. The secondary antibody step used an Alexa 594-conjugated goat anti-rabbit reagent (Invitrogen) at a 1:400 dilution in TBS/T, with coverslips mounted using DAPIcontaining Vectashield Hard-Set mounting medium (Vector).
Statistical analysis. Tests for statistical significance used the non-parametric Mann-Whitney U-test with a 95\% confidence interval.

\section{Conflict of Interest}

The authors declare no conflict of interest.

Acknowledgements. This work was supported by a Cancer Research UK programme grant, we also gratefully thank $M$ Bishop for providing mouse genotyping services, A Hayes for performing confocal fluorescence immunohistochemistry, C Oliver for preliminary data and thank $L$ Parry for providing two cycles of Cre induction small-intestine slides.

1. Schindler C, Darnell JE. Transcriptional responses to polypeptide ligands - the JAK-STAT pathway. Ann Rev Biochem 1995; 64: 621-651.

2. Zhong Z, Wen ZL, Darnell JE. STAT3 - a STAT family member activated by tyrosine phosphorylation in response to epidermal growth factor and interleukin-6. Science 1994; 264: 95-98.

3. Yu H, Jove R. The stats of cancer - new molecular targets come of age. Nat Rev Cancer 2004; 4: 97-105.

4. Haura EB, Turkson J, Jove R. Mechanisms of disease: insights into the emerging role of signal transducers and activators of transcription in cancer. Nat Clin Pract Oncol 2005; 2: 315-324

5. Niwa H, Burdon T, Chambers I, Smith A. Self-renewal of pluripotent embryonic stem cells is mediated via activation of STAT3. Genes Dev 1998; 12: 2048-2060.

6. Dyce PW, Zhu H, Craig J, Li JL. Stem cells with multilineage potential derived from porcine skin. Biochem Biophys Res Comm 2004; 316: 651-658.

7. Oh $\mathrm{IH}$, Eaves CJ. Overexpression of a dominant negative form of STAT3 selectively impairs hematopoietic stem cell activity. Oncogene 2002; 21: 4778-4787.

8. Barker N, van de Wetering M, Clevers H. The intestinal stem cell. Genes Dev 2008; 22 : 1856-1864.

9. Potten CS, Booth C, Pritchard DM. The intestinal epithelial stem cell: the mucosal governor. Int J Exp Path 1997; 78: 219-243.

10. Cheng $\mathrm{H}$, Leblond $\mathrm{CP}$. Origin, differentiation and renewal of the four main epithelial cell types in the mouse small intestine $\mathrm{V}$. Unitarian theory of the origin of the four epithelial cell types. Am J Anat 1974; 141: 537-561.

11. Barker N, van Es JH, Kuipers J, Kujala $P$, van den Born M, Cozijnsen M et al. Identification of stem cells in small intestine and colon by marker gene Lgr5. Nature 2007; 449: 1003-1007.

12. Sato T, Vries RG, Snippert HJ, van de Wetering M, Barker N, Stange DE et al. Single Lgr5 stem cells build crypt-villus structures in vitro without a mesenchymal niche. Nature 2009; 459: 262-265.

13. Ireland H, Kemp R, Houghton C, Howard L, Clarke AR, Sansom OJ et al. Inducible Cre-mediated control of gene expression in the murine gastrointestinal tract: effect of loss of beta-catenin. Gastroenterology 2004; 126: 1236-1246.

14. Takeda K, Kaisho T, Yoshida N, Takeda J, Kishimoto T, Akira S. Stat3 activation is responsible for IL-6-dependent $\mathrm{T}$ cell proliferation through preventing apoptosis: generation and characterization of T cell-specific Stat3-deficient mice. J Immunol 1998; 161: 4652-4660.

15. Ireland $\mathrm{H}$, Houghton $\mathrm{C}$, Howard L, Winton DJ. Cellular inheritance of a Cre-activated reporter gene to determine Paneth cell longevity in the murine small intestine. Dev Dynam 2005; 233: 1332-1336.

16. Takeda K, Noguchi K, Shi W, Tanaka T, Matsumoto M, Yoshida N et al. Targeted disruption of the mouse Stat3 gene leads to early embryonic lethality. Proc Natl Acad Sci USA 1997; 94: 3801-3804.

17. Bowman T, Broome MA, Sinibaldi D, Wharton W, Pledger WJ, Sedivy JM et al. Stat3-mediated Myc expression is required for Src transformation and PDGF-induced mitogenesis. Proc Natl Acad Sci USA 2001; 98: 7319-7324.

18. Moreno E, Basler K. dMyc Transforms cells into super-competitors. Cell 2004; 117: 117-129.

19. Sangiorgi $\mathrm{E}$, Capecchi MR. Bmi1 is expressed in vivo in intestinal stem cells. Nat Genet 2008; 40: 915-920.

20. Ho L, Jothi R, Ronan JL, Cui K, Zhao K, Crabtree GR. An embryonic stem cell chromatin remodeling complex, esBAF, is an essential component of the core pluripotency transcriptional network. Proc Natl Acad Sci USA 2009; 106: 5187-5191.

21. Ura H, Usuda M, Kinoshita K, Sun C, Mori K, Akagi T et al. STAT3 and Oct-3/4 control histone modification through induction of Eed in embryonic stem cells. J Biol Chem 2008; 283: 9713-9723.

22. Lessard J, Schumacher A, Thorsteinsdottir U, van Lohuizen M, Magnuson T, Sauvageau G. Functional antagonism of the Polycomb-group genes eed and Bmi1 in hemopoietic cell proliferation. Genes Dev 1999; 13: 2691-2703. 